\title{
Clinical and radiographic outcomes for microsurgical unilateral laminotomy for bilateral decompression of lumbar spinal stenosis for elderly patients-A retrospective cohort study
}

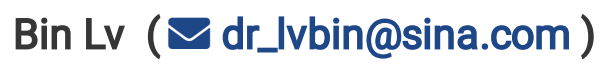

Research article

Keywords: Unilateral laminotomy, Bilateral decompression, Minimally invasive approach, Elderly patients, Lumbar spinal stenosis, Quality of life

Posted Date: May 1st, 2020

DOI: https://doi.org/10.21203/rs.3.rs-23512/v1

License: (c) (i) This work is licensed under a Creative Commons Attribution 4.0 International License.

Read Full License 


\section{Abstract}

\section{Background}

Recently, unilateral laminotomy for bilateral decompression (ULBD) has become a alternative to conventional decompression for symptomatic lumbar spinal stenosis (LSS), and this minimally invasive surgical technique has shown a satisfactory outcomes and low complications. However, the influence of old age on the risk of postoperative complications and clinical outcome is not well understood.

\section{OBJECTIVE}

The purpose of this study was to evaluate clinical and radiographic outcomes and complication rates after ULBD in elderly patients.

Study Design

Single center retrospective observational study.

Setting

All data was from the affiliated people's hospital of Jiangsu University.

\section{METHODS}

In this study, 39 elderly patients were treated for lumbar spinal stenosis by ULBD between January 2016 and January 2018. Follow-up consisted of radiologic investigations, Visual Analog Scale, Oswestry Disability Index, and 36-Item Short-Form Health Survey at 6 and 12 months postoperatively. Preoperative comorbidity, postoperative complications and revision surgery rates were also analyzed.

\section{RESULTS}

There were 12 female patients and 27 male patients with a mean age of $75.83 \pm 9.16$ years. 20 patients had one levels of spinal stenosis, 13 patients had two levels of stenosis, 6 patients had three levels of stenosis. Average follow-up time was $14.6 \pm 7.8$ months (range, 6-24 months), Total complications were $10.2 \%(4 / 39)$,and reoperation rate was $2.5 \%(1 / 39)$. Oswestry Disability Index scores decreased significantly (from $32.26 \pm 6.82$ to $11.44 \pm 2.50$ at 6 months and $10.56 \pm 2.29$ at 12 months), and 36 -Item Short-Form Health Survey parameter scores demonstrated a significant improvement in the follow-up results.

\section{Limitation}

A multi-center study is recommended to confirm our findings and explore the factors related to clinical and radiographic outcomes. 
ULBD for lumbar spinal stenosis is a safe and effective treatment for elderly patients, improves these patients' quality of life and does not pose an increased risk of complications.

\section{Introduction}

The growth in the aging population in recent times hasbeen accompanied by an increase in the prevalence of degenerative spinal diseases. Lumbar spinal stenosis(LSS) is a condition that causes low back pain, leg pain, intermittent claudication and neurological disorders. Symptomatic LSS can have a severe impact on functionality and quality of life and remains the most common indication for surgical intervention on the spine[1,2]. The primary objective of surgical intervention for LSS is decompression of the symptomatic neural elements and to preserve or achieve mechanicalstability[3].

Conventional laminectomy is a straightforward surgical procedure providing adequate decompression and have good-to-excellent outcomes in $64 \%$ of patients[4]. However, using this treatment modality results in the loss of important posterior elements that are necessary for spinal stability; italso causes damage to the facet joint frequently. Consequently,the procedure may lead to spinal instability and secondary intervertebral fixation and fusion. Therefore, many geriatricpatients are reluctant to undergo such surgeries, based on thebelief that old patients are at high risk for serious surgical complications,poor outcome, and even mortality.

Recently, a minimally invasive technique that has gained popularity over the pastyears is unilateral laminotomy for bilateral decompression(ULBD), the procedure requires aunilateral exposure and muscle retraction, thereby minimizingiatrogenic injury to the paraspinalmusclesandthe spinous process/interspinousligament midline tension band structures[5] (Fig. 1).This approach significantlyreduces soft tissue injury and intraoperative bleeding.As aresult, patients experience less postoperative pain and canusually be mobilized and discharged early.

Since elder patients may have comorbidities, it is important toconsider those parameters in choosing appropriate surgical interventions for this age group.For this reason, a appropriate operative procedure should be used to answer two major questions:(1)Does this procedure decrease morbidity and mortality rates? (2)Does this procedure decompress the neural elements adequately to improve symptoms? Therefore, the aim of the present study was to evaluate complication rates and outcomes after minimally invasive ULBD in elderly patients.

\section{Materials And Methods}

After approval from approved by the Ethics Committee of the Affiliated People's Hospital of Jiangsu University, were retrospectively collected medical records of patients who underwent ULBD lumbar decompression surgery between January 2016 and January 2018. All surgeries were performed by one senior chief surgeon. Inclusion criteria included LSS patients older than 65 years .Patients excluded from the study were those who had a previous history of LSS surgery, spinal instability, lumbar 
spondylolisthesis, overweight patients with a body mass index(BMI) over 40,psychiatricdisorders such as schizophrenia, schizoaffective disorder, bipolar disorder and major depressive disorder, peripheral neurological disease, or severe heart, lung, kidney, or liver disease.

The study cohort included a total of 39 patients. Demographic data and preoperative Data(Table 1), including medical history, medical comorbidities, BMI , and American Society of Anesthesiologists (ASA) score, were recorded. To simplify the presentation of the medical history data, we classified patients' comorbidities into 7 categories: cardiac, endocrine, metabolic, gastrointestinal, pulmonary, renal, multiple comorbidity. Operative data included number of operated spinal level, operation time and blood loss. Clinical outcomes included hospital length of stay, postsurgical complications, revision surgery, and mortality. Preoperative and postoperative cross-sectional area of the lumbar spinal canal was calculated from computed tomography (CT).

Follow-up consisted of the Visual Analog Scale (VAS), Oswestry Disability Index (ODI) questionnaire and 36-Item Short-Form Health Survey (SF-36) 6 and 12 months postoperatively. Flexion-extension lumbar radiographs were obtained again at 6,12 months postoperatively and spinal instability was defined as a sagittal plane translation of $\geq 5 \mathrm{~mm}$ on flexion-extension radiographs (Radiological evaluation was judged by two observers blinded). Patient-reported outcomes were collected via face-to-face assessment or by using telephone interviews.

\section{Unilateral Laminotomy For Bilateral Decompression Technique}

The microscopic decompression procedure has been previously described[6, 7]. In brief, we made a $3-5 \mathrm{~cm}$ midline incision after fluoroscopic confirmation of surgical level. After skin incision, the multifidusmuscle was dissected unilaterally from the spinous process and lamina using a Cobb elevator and retracted by aTaylor retractor. After detachment of paraspinal muscles, ipsilateral laminotomy was performed using a burrand Kerrison punches, followed by flavectomy using microscope. To view the contralateral side, the operationtable and microscope were tilted approximately 15 to $25^{\circ}$. For decompression, undercutting of the spinousprocess and contralateral lamina was performed using a burr and Kerrison punches, followed by flavectomy.After contralateral laminotomy and flavectomy, complete neural decompression was confirmed by restorationof dural pulsation(Fig. 2).

\section{Statistics}

All statistical analyses were performed using SPSS 15.0(SPSS, Inc., Chicago, IL, USA). The KolmogorovSmirnov test wasused to determine whether the distributions were significantlydifferent. The data are shown as the mean \pm standard deviationfor continuous variables, the median (maximum-minimum) forordinal variables, and the frequency with percent for categoricalvariables. A one-way analysis of variance (ANOVA) was used to assessthe significant differences between groups. TheKruskal-Wallis test 
was employed to compare nonparametric dataand to test the significant differences between median values. Thechi-square test was used for categorical comparisons. In case ofmultiple comparisons, the Bonferroni adjustment was used to control type I errors; and P-value less than 0.05 was considered statistically significant.

\section{Results}

A total of 39 patients ( 12 female, 27 male) with spinal stenosis were included in the study. The mean age of the patients was75.83 \pm 9.16 years (range, $65-87$ years). 22 patients had one levels of spinal stenosis, 11 patients had two levels of spinal stenosis, 6 patients had three levels of spinal stenosis. Average follow-up time was 14 months (range, 6-24 months). No cases of infection were found in our study. The operation time, blood loss and length of hospitalization were recorded (Table 2). There were total four complications, two dural tear (repaired primarily),one neurologic deficit (postoperativeweakness of great toe dorsiflexion on the contralateral operative side,which was relieved spontaneously),one symptom was no improvement(reoperation with laminectomy and fusion).

\section{Radiographic Analysis}

CT showed the mean postoperative cross-sectional area of the spinalcanal were more significant larger than preoperation and mean postoperative lateral recess height were higher than before surgery(Fig. 34),these results were not significant between 6 months and 12 months follow-up (Table 3). No signifcant abnormal motion in the sagittal planes were observed on flexion-extension lumbar radiographsat 6 and 12 months postoperatively, compared with the preoperation (Table 3 ).

\section{Clinical Outcomes}

Analysis of low back and leg pain VASscores showed significant improvements in clinicaloutcomes from before surgery to 6 months and 12 months after surgery(Tables 4). However, these changes were not significantbetween 6 months and 12 months during follow-up period.

ODI scores decreased significantly in 6months and 12 months follow-up, evaluations from a mean preoperative score of $31.37 \pm 8.61$ to $12.44 \pm 3.50$ at 6 months and $12.30 \pm 2.67$ at 12 months, (Table 4), and we did not detect the significant differences in 6 months and 12 months.

Comparison of preoperative and 6months and 12months follow-up, SF-36 scores demonstrated a significant improvementexcept in the areas of emotional role.There were no significant differences in 6 months and 12 months scores of SF-36(Table 4).

\section{Discussion}


In the elderly population, low back pain is a very common healthissue. Degenerative lumbar stenosis is one of the most commoncauses of these conditions. Randomized trials indicate that for symptomatic LSS patients, decompression offers greater efficacy than nonsurgical treatments[6]. However, the effect of ageas an independent risk factor is well understood, it has beenrelated to an increased risk of morbidity after open spine surgery[8].Other studies havefound morbidity andcomplication rates were higher in elders comparedwith younger patients after spine surgery, and this finding might be due to the highprevalence of multiple medical comorbidities in this aged group $[9,10]$.Therefore, it is very important to make a choice which surgical procedure is appropriate, especially in geriatric patients ,for whom the surgical challenge is their physical, psychologic, and social frailty. For this reason,simple Minimally invasive surgical (MIS) decompression surgery methods were preferred to decreasemorbidity and mortality rates.

MIS approaches involvemuscle-splitting techniques to access the spine, leavingintact the midline structures that support muscles andligamentsand decreasing intraoperative blood loss andpostoperative pain[11]. One such recently described MIStechnique is unilateral laminotomy for bilateral decompression (ULBD). This technique uses the microendoscopictubular-retractor system to preserve the facet joints and neural arch ofthe contralateral side, limits postoperative destabilization, andprotects the neural structures from extensive trauma.Ang et al[12], retrospectively reviewed the outcomes of 113 patients, measured by VAS for back and leg pain, the North American Spine Society score on neurogenic symptoms, found they were comparable between the ULBD and the open lumbar laminotomy groups,but ULBD was associated with the lower blood loss, the shorter hospital stay, the lower percentage of complications and the need for revisions.Although other studies have confirmed similar results[13], however, for elderly LSS patients over 75 years old, studies on the complications, clinical and radiographic outcomes of ULBD surgeries have seldom been reported.

In this study, the mean age of patients was 75.83 years, and nearly half of these patients had two or more levels of stenosis. We found that ULBDwas associated withsignificant improvement in low back and leg pain as well asODI and SF-36 at 6 months in most patients, thisimprovement persisted at 12 months follow-up. Moreover, patients in the current series toleratedthe surgical procedure well, even though many had comorbiditiessuch as hypertension, congestive heart failure, diabetes mellitus, chronic obstructive pulmonary disease. Katz et al[14].found that after decompressive laminectomy, elderly patients with greater medical comorbidity andfunctional disability were significantly less satisfied with theresults of surgery. Transfeldtetal[15]. reported that patients undergoing open surgical decompression, with anaverage age of 76.4 years, the complication rate was $21 \%-40 \%$.In our study the total complication rate were $10.2 \%$ and these results demonstated that satisfactory outcomes in elderly patients. We speculate that these good outcomes and low complications of theULBD resultfrom several inherent advantages of the MIS technique. MIS technique can reduce theinflammatory and stress response after surgery. Postsurgical stressresponse was found to contribute to imbalance in autonomic,endocrine, and immune systems. It was also found to promotehypertension, cardiac dysrhythmias, and myocardial infarctions inthe immediate perioperative period[16].Elderly frail patientssuffering from multiple medical 
comorbidities and limited physiologicreserve are vulnerable to stress and may therefore especiallybenefit from MIS procedures that minimize these risks.

Another advantage of ULBD is the decreased wound infection. Aging and a comorbid condition, such as vasculopathy, can leadto delayed wound healing that may jeopardize patient outcomeseither by direct influence on spinal muscle rehabilitation[17]. ULBD surgery results insmaller skin incisions that facilitate wound healing and decreasethe risk of wound complications in old population, maybe for this reason ,no wound infections in our study. And this MIS procedure also can reduce blood loss[18].The cardiovascular and pulmonary compensatory mechanisms areof limited capacity in older patients because age decreases thecontractility and increases the stiffness of the left ventricle[19].These alterations may impair the patient from tolerating largevolume shifts, which can lead to life-threating complications ingeriatric patients.

Dural tears were the most common complication in UBLD. Itwas thought that with the unilateral approach, especially in severe elderly LSS patients, accessto the opposite lateral spinal canal may require significant duralsac retraction, with a possibly higher risk of tears of the spinaldura mater. Accidental dural tears occurred in 2 patients (4.4\%) inour study. However, the rate of dural tears in our serieswas similar to the previously documented average results formicrosurgical ULBD of LSS (0\%-18\%)[18].This rate was comparableor lower than the rates reported in most series ofdecompressive surgery for LSS with a published overall incidenceof dural tears approaching 14\%[20]. To our experiences, in cases withbilateral radiculopathy or severe stenosis, do not rush this stage of the procedure. Allowing contralateralmicroscopic visualization and using angled curets slowly create more room to perform the decompression could reduce the incident of dural tears. If an iatrogenic injury to the dura is encountered, it is best to close it immediately. This mayrequire some special long shaft suture instruments to achievewatertight closure.

For ULBD, another main goal of surgery was adequate decompression of the neural elements. We utilized CT to measurements of the cross-sectional area of the spinal canal and lateral recess heights and postoperative CT demonstrated decompression was enough. In contrast to our results, Thomé et al. [21]found that the ULBD was associated with less sufficient decompression than the bilateral laminotomy, even if the difference was not significant. This finding may suggest that the ULBD approach provides a worse view of the contralateral recess due to the limited exposure via a unilateral approach. However, Moisi et al[22]. concluded in their technical note that the ULBD approach could provide better visualization of the contralateral recess. Our selection of the decompression strategy using the ULBD technique was based on patients' symptoms and severity of LSS. For elderly patients with facet hyperplasia, ipsilateral facetectomy was routinely performed to obtain an adequate decompression for foraminal and lateral recess stenosis,it provided enough space and abduction angle to allow undermining of the ventral aspect of the spinous process and contralateral lamina, and the posterior midline osteoligamentous structures and contralateral ligamentum flavum could be resected to expose the contralateral side, which allow contralaterally facetectomy and provide complete decompression of the dural sac and contralateral nerve root. 
During lumbar decompression surgery, the extent of preservationof the bilateral facet joint is an important factor for maintianing spinal stability[23]. Traditional standard decompressioninvolves widely facetectomy andsome removal of the posterior spinal structures. As aresult, the approach can lead to postoperative destabilization, which canlead to the need for spinal fusionand in turn is associatedwith increased comorbidities in elderly patients. Maricondaet al[24]. indicated that high rates of reoperation in opendecompression, ranged $11-30 \%$. In our study, we performed adequate decompression of the spinal stenosis and no secondary instability was found in this ULBD procedure. Miyazakiet al[25].reported the average percent facet joint preservation on ULBD was significantly smaller in conventional decompression surgery, ULBD preserved $60-83 \%$ of the facet joint on the approach side and $>90 \%$ of the facet joint on the contralateralside. By contrast, traditional approach only retain $\leq 40 \%$ percent of the facet[26]. Therefore, we thought this MIS method can reduce the risk of postoperative spinal instability at the surgical site due to satisfactory preservation of the facet joint.

\section{Conclusions}

Our experience supports the use of the ULBD as a lessinvasive technique for symptomatic LSS to conservativetreatment that allows for adequate decompression ofneural elements at the affected level. After the relief of symptoms, the general health and mental conditions of patients can also be significantly improved. The results of this study indicate thatULBDsurgery is a safe and effective treatment for elderly patientsand does not pose an increased risk of complications.

\section{Limitations}

Our study has several limitations. First of all we have our study with a limited number of patients, the sample size was not sufficient to yield substantial effects. Second limitation, we were not able to compare beneficial results from ULBD inthis age group with outcomes from those of an open surgical intervention in a similar age-grouped patient cohort. Finally, this was a retrospective study, and the indications for this surgicalprocedure were limited inpatients with LSS. Additional studies with larger samples and longer follow-up periods should be performed to confirm the present results.

\section{Abbreviations}

\section{ULBD}

Unilateral laminotomy for bilateral decompression

LSS

Lumbar spinal stenosis

ODI

Oswestry Disability Index

SF-36

36-Item Short-Form Health Survey

ASA 


\section{Declarations}

\section{Ethics approval and consent to participate}

Ethical approval for this study was granted by the Affiliated People's Hospital of Jiangsu University, China, and all patients or authorized relatives gave informed consent

\section{Consent for publication}

We have obtained consent for publication.

\section{Availability of data and materials}

Data will not be available because consent and ethical approval was not obtained for sharing. Additionally, all available data has been summarized in the text of the manuscript.

\section{Competing interests}

The authors declare that they have no competing interests.

\section{Foundation}

This study was supported by Science and Technology Planning Social Development Project of Zhenjiang City, Jiangsu Province (SH2018040).

\section{Authors' contributions}

BL brought forward the subject and guided the writing. BL drafted the manuscript. BL performed the critical editing and participated in the constructive outline, discussions, and editing. All authors read and approved the final manuscript.

\section{Acknowledgments}

The authors thank Yan Zhou and Tao Liu for radiology preparation.

\section{References}

1. Garfin SR, Herkowitz HN, Mirkovic S. Spinal stenosis. Instr Course Lect. 2000;49:361-74.

2. Katz JN, Stucki G, Lipson SJ, Fossel AH, Grobler LJ, Weinstein JN. Predictors of surgical outcome in degenerative lumbar spinal stenosis. Spine (Phila Pa 1976). 1999;24(21):2229-33.

3. Weinstein JN, Tosteson TD, Lurie JD, Tosteson AN, Blood E, Hanscom B, Herkowitz H, Cammisa F, Albert T, Boden SD, et al. Surgical versus nonsurgical therapy for lumbar spinal stenosis. $\mathrm{N}$ Engl $\mathrm{J}$ 
Med. 2008;358(8):794-810.

4. Turner JA, Ersek M, Herron L, Deyo R. Surgery for lumbar spinal stenosis. Attempted meta-analysis of the literature. Spine (Phila Pa 1976). 1992;17(1):1-8.

5. Mikami Y, Nagae M, Ikeda T, Tonomura H, Fujiwara H, Kubo T. Tubular surgery with the assistance of endoscopic surgery via midline approach for lumbar spinal canal stenosis: a technical note. Eur Spine J. 2013;22(9):2105-12.

6. Raffo CS, Lauerman WC. Predicting morbidity and mortality of lumbar spine arthrodesis in patients in their ninth decade. Spine (Phila Pa 1976). 2006;31(1):99-103.

7. Scholler K, Steingruber T, Stein M, Vogt N, Muller T, Pons-Kuhnemann J, Uhl E. Microsurgical unilateral laminotomy for decompression of lumbar spinal stenosis: Iong-term results and predictive factors. Acta Neurochir (Wien). 2016;158(6):1103-13.

8. Arinzon ZH, Fredman B, Zohar E, Shabat S, Feldman JS, Jedeikin R, Gepstein RJ. Surgical management of spinal stenosis: a comparison of immediate and long term outcome in two geriatric patient populations. Arch Gerontol Geriatr. 2003;36(3):273-9.

9. Guha D, Heary RF, Shamji MF. latrogenic spondylolisthesis following laminectomy for degenerative lumbar stenosis: systematic review and current concepts. Neurosurg Focus. 2015;39(4):E9.

10. Kim HS, Paudel B, Jang JS, Oh SH, Lee S, Park JE, Jang IT. Percutaneous Full Endoscopic Bilateral Lumbar Decompression of Spinal Stenosis Through Uniportal-Contralateral Approach: Techniques and Preliminary Results. World Neurosurg. 2017;103:201-9.

11. Spetzger U, Von Schilling A, Winkler G, Wahrburg J, Konig A. The past, present and future of minimally invasive spine surgery: a review and speculative outlook. Minim Invasive Ther Allied Technol. 2013;22(4):227-41.

12. Ang CL, Phak-Boon Tow B, Fook S, Guo CM, Chen JL, Yue WM, Tan SB. Minimally invasive compared with open lumbar laminotomy: no functional benefits at 6 or 24 months after surgery. Spine J. 2015;15(8):1705-12.

13. Storzer B, Schnake KJ. Microscopic bilateral decompression by unilateral approach in spinal stenosis. Eur Spine J. 2016;25(Suppl 2):270-1.

14. Katz JN, Lipson SJ, Brick GW, Grobler LJ, Weinstein JN, Fossel AH, Lew RA, Liang MH. Clinical correlates of patient satisfaction after laminectomy for degenerative lumbar spinal stenosis. Spine (Phila Pa 1976). 1995;20(10):1155-60.

15. Transfeldt EE, Topp R, Mehbod AA, Winter RB. Surgical outcomes of decompression, decompression with limited fusion, and decompression with full curve fusion for degenerative scoliosis with radiculopathy. Spine (Phila Pa 1976). 2010;35(20):1872-5.

16. Bingqian C, Feng X, Xiaowen S, Feng Z, Xiaowen F, Yufeng Q, Qirong D. Modified posterior lumbar interbody fusion using a single cage with unilateral pedicle screws: a retrospective clinical study. J Orthop Surg Res. 2015;10:98.

17. Rahman M, Summers LE, Richter B, Mimran RI, Jacob RP. Comparison of techniques for decompressive lumbar laminectomy: the minimally invasive versus the "classic" open approach. 
Minim Invasive Neurosurg. 2008;51(2):100-5.

18. Sidhu GS, Henkelman E, Vaccaro AR, Albert TJ, Hilibrand A, Anderson DG, Rihn JA. Minimally invasive versus open posterior lumbar interbody fusion: a systematic review. Clin Orthop Relat Res. 2014;472(6):1792-9.

19. Severn A. Anaesthesia and the preparation and management of elderly patients undergoing surgery. Eur J Cancer. 2007;43(15):2231-4.

20. Mayer HM, List J, Korge A, Wiechert K. [Microsurgery of acquired degenerative lumbar spinal stenosis. Bilateral over-the-top decompression through unilateral approach]. Orthopade. 2003;32(10):889-95.

21. Thome C, Zevgaridis D, Leheta O, Bazner H, Pockler-Schoniger C, Wohrle J, Schmiedek P. Outcome after less-invasive decompression of lumbar spinal stenosis: a randomized comparison of unilateral laminotomy, bilateral laminotomy, and laminectomy. J Neurosurg Spine. 2005;3(2):129-41.

22. Moisi M, Fisahn C, Tkachenko L, Tubbs RS, Ginat D, Grunert P, Jeyamohan S, Reintjes S, Ajayi O, Page $\mathrm{J}$, et al. Unilateral Laminotomy with Bilateral Spinal Canal Decompression for Lumbar Stenosis: A Technical Note. Cureus. 2016;8(5):e623.

23. Deyo RA, Martin BI, Kreuter W, Jarvik JG, Angier H, Mirza SK. Revision surgery following operations for lumbar stenosis. J Bone Joint Surg Am. 2011;93(21):1979-86.

24. Mariconda M, Fava R, Gatto A, Longo C, Milano C. Unilateral laminectomy for bilateral decompression of lumbar spinal stenosis: a prospective comparative study with conservatively treated patients. J Spinal Disord Tech. 2002;15(1):39-46.

25. Miyazaki M, Morishita Y, Takita C, Yoshiiwa T, Wang JC, Tsumura H. Analysis of the relationship between facet joint angle orientation and lumbar spine canal diameter with respect to the kinematics of the lumbar spinal unit. J Spinal Disord Tech. 2010;23(4):242-8.

26. Sasai K, Umeda M, Maruyama T, Wakabayashi E, lida H. Microsurgical bilateral decompression via a unilateral approach for lumbar spinal canal stenosis including degenerative spondylolisthesis. $J$ Neurosurg Spine. 2008;9(6):554-9.

\section{Tables}

Table 1Patient demographics and comorbidies 


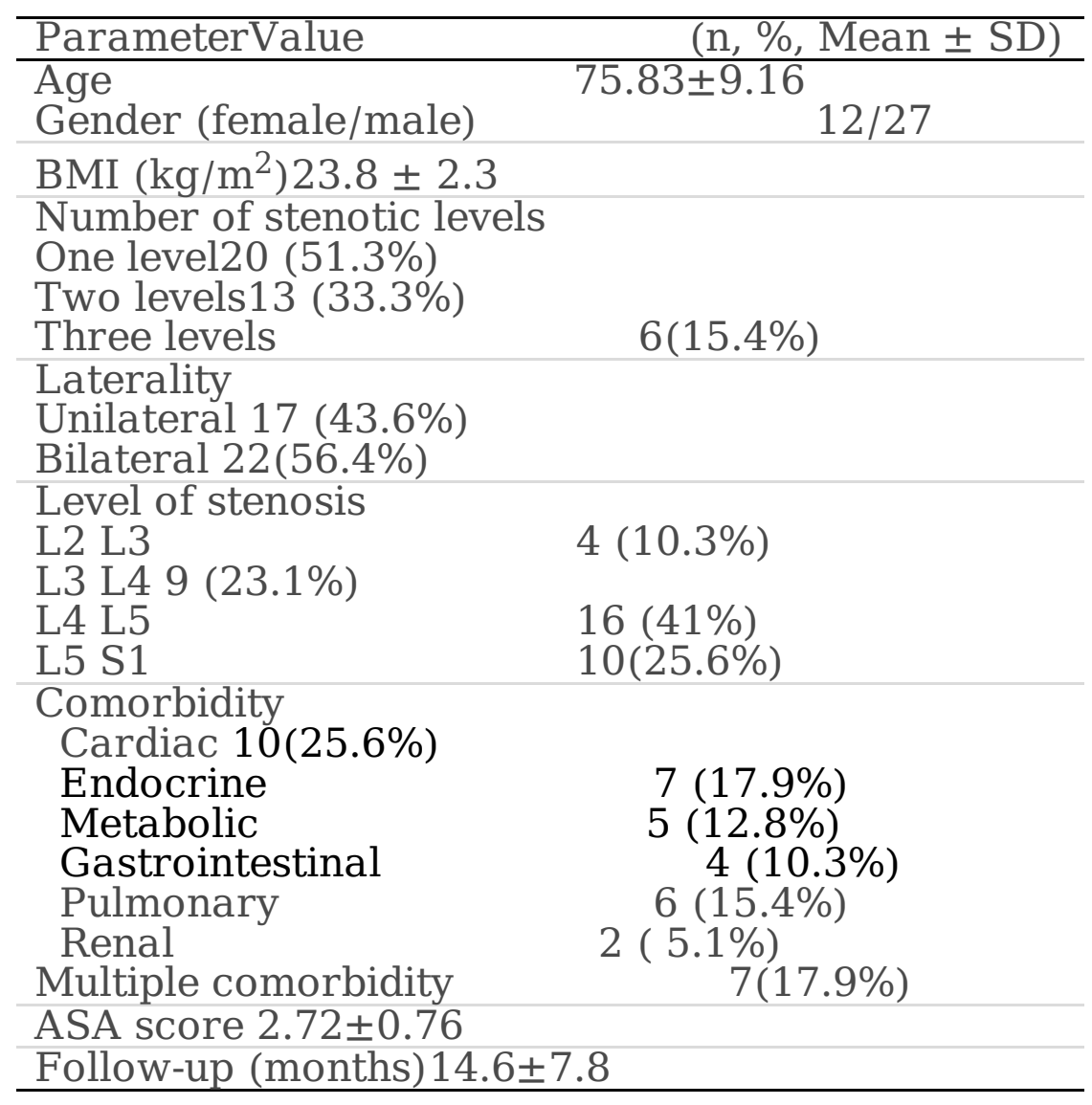

Table 2 operative data

\begin{tabular}{lc}
\hline Parameter & Value(n, \%, Mean \pm SD) \\
\hline Duration of operation (min) & $45.2 \pm 9.4$ \\
1-level op & $88.5 \pm 17.4$ \\
2-level op & $133.6 \pm 37.5$ \\
3-level op & $80.5 \pm 12.8$ \\
Estimated blood loss (mL) & \\
1-level op & $279.4 \pm 70.3$ \\
2-level op $145.7 \pm 55.7$ & $4 / 10.3 \%$ \\
3-level op & Length of hospitalization (d) $5.4 \pm 1.9$ \\
Total complications (n/rate) & $2 / 5.1 \%$ \\
Dural tear & $1 / 2.6 \%$ \\
Neurologic deficit & $1 / 2.6 \%$ \\
\hline
\end{tabular}

Table 3 Comparison of RadiographicdataPreoperatively, at 6 months Follow-Up, and at 12 MonthsFollow-Up for Patients( Mean \pm SD) 


\begin{tabular}{|c|c|c|c|c|}
\hline & Preoperation & $6 \mathrm{~m}$ & $12 \mathrm{~m}$ & P-value \\
\hline $\begin{array}{l}\text { Jss-sectional } \\
\text { əа }\left(\mathrm{mm}^{2}\right)\end{array}$ & $55.8 \pm 26.6$ & $138.8 \pm 30.5$ & $135.2 \pm 35.7$ & $\begin{array}{l}\mathrm{P}_{6 \mathrm{~m}-} \\
\text { po }=0.001 \\
\mathrm{P}_{6 \mathrm{~m}-} \\
12 \mathrm{~m}=0.27\end{array}$ \\
\hline $\begin{array}{l}\text { ilateral lateral } \\
\text { sess height }(\mathrm{mm})\end{array}$ & $1.8 \pm 0.6$ & $4.6 \pm 2.2$ & $4.4 \pm 1.6$ & $\begin{array}{l}\mathrm{P}_{6 \mathrm{~m}-} \\
\text { po }=0.01 \\
\mathrm{P}_{6 \mathrm{~m}-} \\
12 \mathrm{~m}=0.53\end{array}$ \\
\hline $\begin{array}{l}\text { ntralateral lateral Recess } \\
\text { ght(mm) }\end{array}$ & $2.5 \pm 0.7$ & $4.1 \pm 1.3$ & $4.0 \pm 0.9$ & $\begin{array}{l}\mathrm{P}_{6 \mathrm{~m}-} \\
\text { po }=0.01 \\
\mathrm{P}_{6 \mathrm{~m}-} \\
12 \mathrm{~m}=0.59\end{array}$ \\
\hline $\begin{array}{l}\text { namicmotion Flexion- } \\
\text { ension }(\mathrm{mm})\end{array}$ & $2.2 \pm 1.5$ & $2.3 \pm 1.7$ & $2.5 \pm 1.4$ & $\begin{array}{l}P_{6 m-p o} \\
=0.72 \\
P_{6 m-} \\
12 \mathrm{~m}=0.35\end{array}$ \\
\hline
\end{tabular}

P6m-pocompared preoperation with6 months follow-Up;

$\mathrm{P}_{6 \mathrm{~m}-12 \mathrm{~m}}$ compared 6 months with12 months follow-Up

Table 4Oswestry Disability Index(ODI), Visual Analog Scale(VAS) and 36-Item Short-Form Health Survey Scores Preoperatively, at 6 Months and 12 Months Follow-Up( Mean \pm SD) 


\begin{tabular}{|c|c|c|c|c|}
\hline & Preoperation & $6 \mathrm{~m}$ & $12 \mathrm{~m}$ & P-value \\
\hline ODI & $31.37 \pm 8.61$ & $12.44 \pm 3.50$ & $12.30 \pm 2.67$ & $\mathrm{P}_{6 \mathrm{~m}-\mathrm{po}}=0.001$ \\
\hline Back pain VAS & $5.4 \pm 1.6$ & $1.8 \pm 0.7$ & $1.9 \pm 0.3$ & $\begin{array}{l}P_{6 m-12 m}=0.38 \\
P_{6 m-p o}=0.001 \\
P_{6 m-12 m}=0.26\end{array}$ \\
\hline Leg pain VAS & $6.6 \pm 2.8$ & $1.4 \pm 0.6$ & $1.2 \pm 0.2$ & $\begin{array}{l}P_{6 m-p o}=0.001 \\
P_{6 m-12 m}=0.17\end{array}$ \\
\hline SF-36 & & & & \\
\hline Physical function & $58.67 \pm 5.23$ & $72.45 \pm 5.31$ & $71.86 \pm 4.68$ & $\begin{array}{l}P_{6 m-p o}=0.001 \\
P_{6 m-12 m}=0.51\end{array}$ \\
\hline Physical role & $29.56 \pm 8.77$ & $49.01 \pm 9.22$ & $49.11 \pm 8.75$ & $\begin{array}{l}\mathrm{P}_{6 \mathrm{~m}-\mathrm{po}}=0.001 \\
\mathrm{P}_{6 \mathrm{~m}-12 \mathrm{~m}}=0.69\end{array}$ \\
\hline Body pain & $40.11 \pm 4.11$ & $68.25 \pm 7.53$ & $68.29 \pm 7.75$ & $\begin{array}{l}\mathrm{P}_{6 \mathrm{~m}-\mathrm{po}}=0.001 \\
\mathrm{P}_{6 \mathrm{~m}-12 \mathrm{~m}}=0.44\end{array}$ \\
\hline General health & $52.27 \pm 4.25$ & $58.26 \pm 3.13$ & $57.23 \pm 4.54$ & $\begin{aligned} \mathrm{P}_{6 \mathrm{~m}-\mathrm{po}} & =0.01 \\
\mathrm{P}_{6 \mathrm{~m}-12 \mathrm{~m}} & =0.39\end{aligned}$ \\
\hline Vitality/energy & $41.73 \pm 3.11$ & $58.97 \pm 5.21$ & $59.12 \pm 5.18$ & $\begin{array}{c}\mathrm{P}_{6 \mathrm{~m}-\mathrm{po}}=0.01 \\
\mathrm{P}_{6 \mathrm{~m}-12 \mathrm{~m}}=0.41\end{array}$ \\
\hline Social function & $40.32 \pm 5.41$ & $51.54 \pm 6.27$ & $52.33 \pm 6.09$ & $\begin{array}{c}\mathrm{P}_{6 \mathrm{~m}-\mathrm{po}}=0.01 \\
\mathrm{P}_{6 \mathrm{~m}-12 \mathrm{~m}}=0.36\end{array}$ \\
\hline Emotional role & $63.62 \pm 5.73$ & $63.72 \pm 5.73$ & $63.69 \pm 5.76$ & $\begin{array}{c}\mathrm{P}_{6 \mathrm{~m}-\mathrm{po}}=0.31 \\
\mathrm{P}_{6 \mathrm{~m}-12 \mathrm{~m}}=0.40\end{array}$ \\
\hline Mental health & $43.36 \pm 5.80$ & $63.37 \pm 5.77$ & $63.34 \pm 5.82$ & $\begin{array}{l}\mathrm{P}_{6 \mathrm{~m}-\mathrm{po}}=0.001 \\
\mathrm{P}_{6 \mathrm{~m}-12 \mathrm{~m}}=0.22\end{array}$ \\
\hline
\end{tabular}

P6m-po compared preoperation with 6 months Follow-Up;

$\mathrm{P}_{6 \mathrm{~m}-12 \mathrm{~m}}$ compared 6 month/ with12 months Follow-Up

\section{Figures}



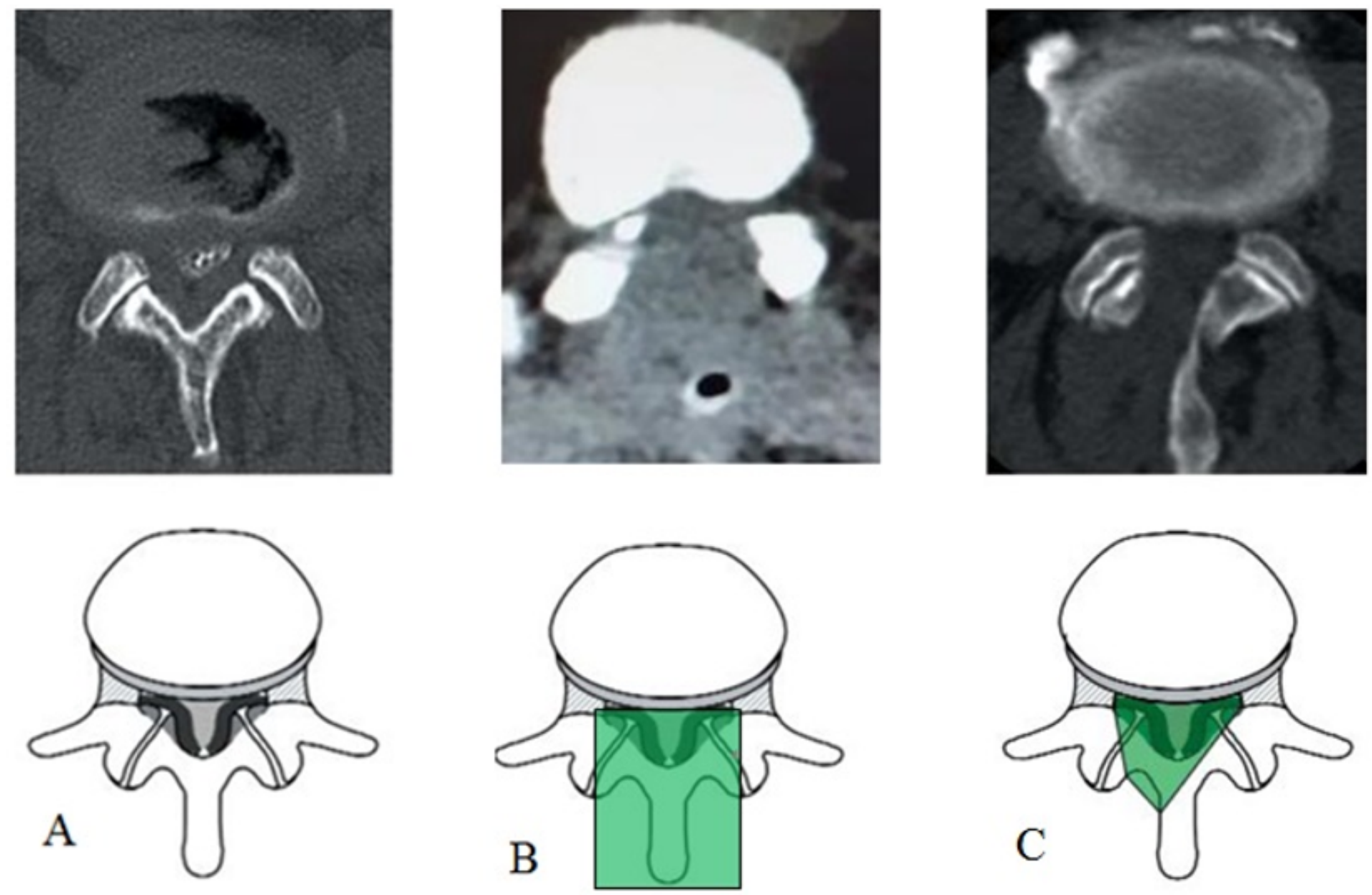

Figure 1

CT scans of tranditional decompression and ULBD procedures. Spinal lumbar canal stenosis(A). Tranditional decompression approach removed most posterior elements and resected a large portion of the bilateral facet joints (B); ULBD indicated that a laminotomy was performed by removing a portion of the superior and inferior laminae at the segment, and a small part of the medial facet. Deep cortical surface of contralateral lamina was undercut and drilling was extended to the contralateral medial facet(C). 


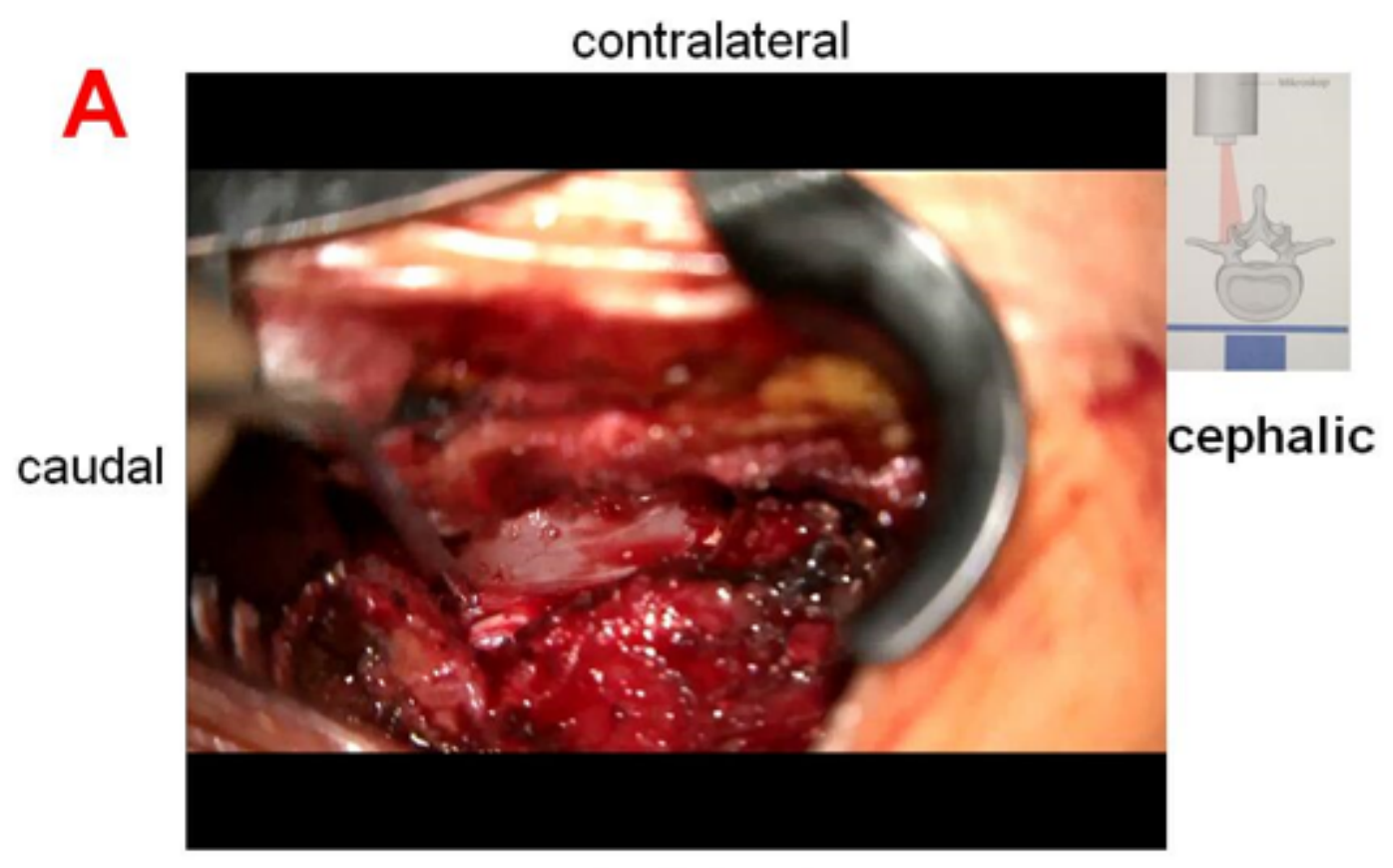

ipsilateral

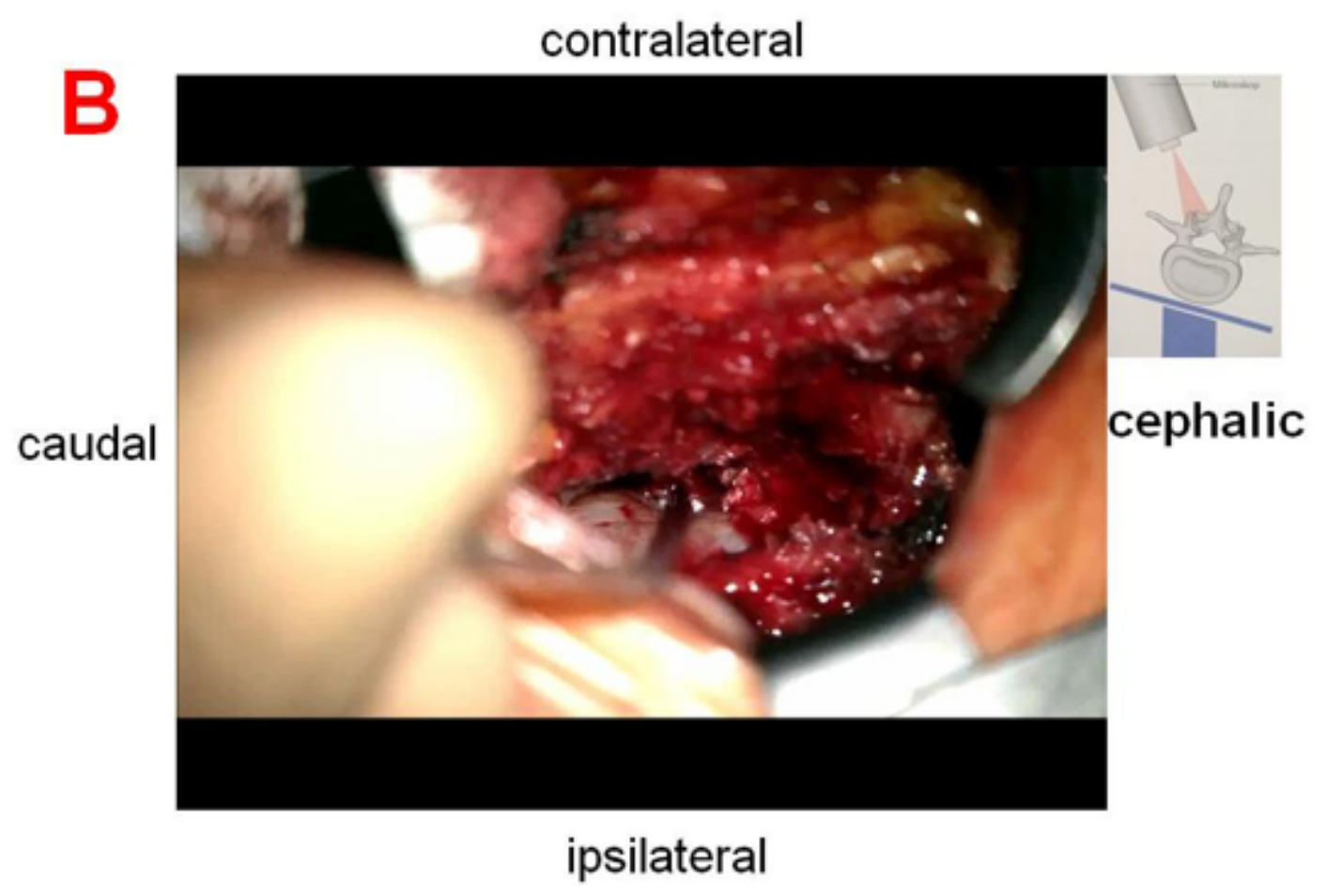

\section{Figure 2}

ULBD for spinal lumbar canal stenosis. The inferior half of the L4 lamina has been drilled and the base of the spinous process to expose the ligamentum flavum bilaterally $(A)$; Decompression of the contralateral side. (B). The tubular retractor is angled beneath the spinous process. 

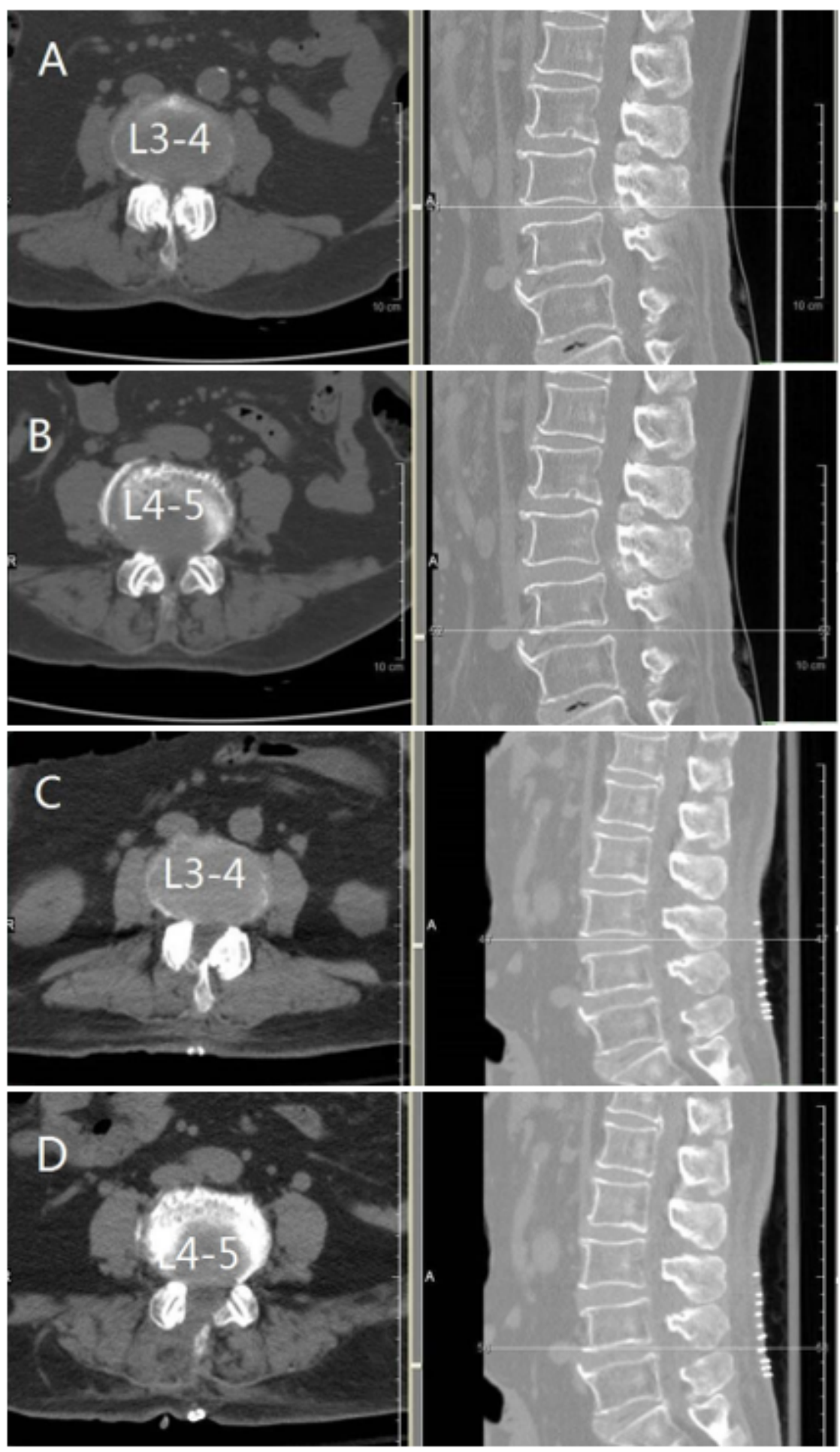

Figure 3

Preoperative computed tomography of L3-L4,L4-L5 stenosis (A-B), and postoperative computed tomography (C-D) obtained in one patient undergoing ULBD for 2-level stenosis. 

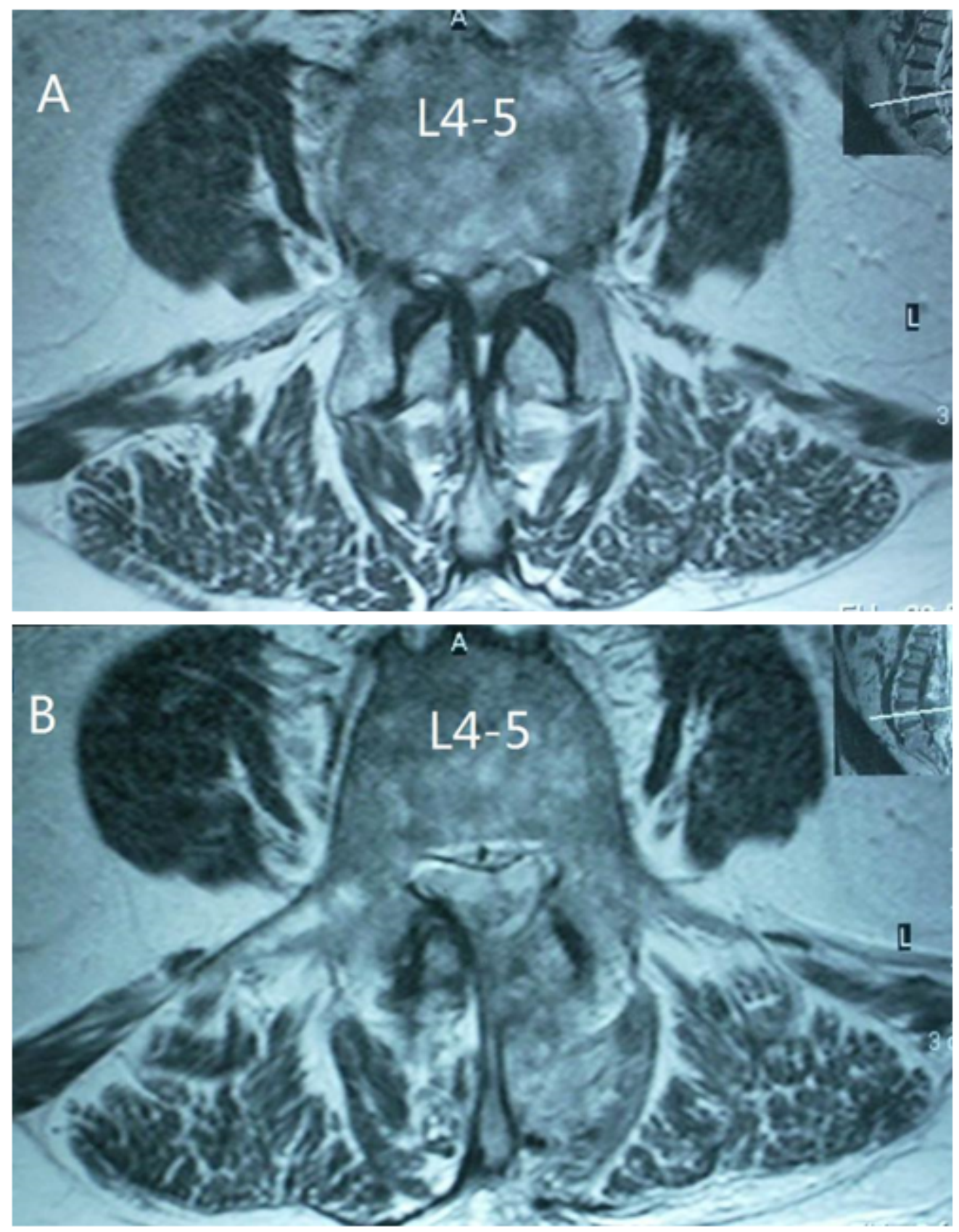

Figure 4

Preoperative (A) and postoperative (B) T2-weighted magnetic resonance imaging of L4-L5 stenosis. 